\title{
Managing life-altering situations: A qualitative longitudinal study of the experiences of people with memory disorders and their family caregivers
}

\author{
Hanna-Mari Pesonen ${ }^{1,2}$, Anne M. Remes ${ }^{3,4}$, Arja I sola ${ }^{1}$ \\ 1. Institute of Health Sciences, Faculty of Medicine, University of Oulu, Oulu, Finland. 2. Oulu University Hospital, Oulu, \\ Finland. 3. Institute of Clinical Medicine, University of Eastern Finland, Kuopio, Finland. 4. Department of Neurology, \\ Kuopio University Hospital, Kuopio, Finland.
}

Correspondence: Hanna-Mari Pesonen. Address: Faculty of Medicine, University of Oulu, Oulu, Finland. Email: hanna-mari.pesonen@oulu.fi

Received: May 25, 2014

DOI : 10.5430/jnep.v4n10p60
Accepted: July 22, $2014 \quad$ Online Published: August 8, 2014

URL: http://dx.doi.org/10.5430/jnep.v4n10p60

\section{Abstract}

Objective: Diagnosis of a family member with a memory disorder creates significant psychosocial coping demands for the whole family. The aim of this study was to examine shared experiences of people with memory disorders and their family caregivers during the first years following diagnosis to construct a substantive theory. The study focused on factors related to mutual processes used for managing such life-altering situations.

Methods: A qualitative longitudinal research design informed by grounded theory was used. Experiences shared by eight people with memory disorders and their closest family caregivers were determined using semi-structured interviews $(\mathrm{n}=$ 23) in their homes. The study participants were recruited from a memory clinic at a tertiary care hospital.

Results: A core category, 'Process of accepting memory disorder as part of family life', and related categories and subcategories were formulated from the data. The subcategories 'Acknowledging available qualities and resources', 'Seeking meaningful social support', and 'Living for today', were mutual components of the categories 'Adjusting to altering self', and 'Adapting to a new caregiver role'. The contents of each subcategory comprise a continuum of positive and negative dimensions of adjustment and distress.

Conclusions: Accepting a memory disorder as part of family life is a mutual process involving concurrent and specific requirements of both people with memory disorders and family caregivers. Acknowledging the potential of the person diagnosed, opportunities for social support, and living for today, reinforce the process of managing life after a memory disorder diagnosis.

\section{Key words}

Memory disorder, Person with memory disorder, Family caregiver, Family dynamics, Experiences, Qualitative studies

\section{I ntroduction}

Alzheimer's disease and other dementias pose major challenges for health and social care worldwide. Over 35 million people are affected by memory disorders and estimates indicate that this number will increase to over 65 million in 2030, 
and over 115 million in $2050{ }^{[1]}$. Memory disorders are neurodegenerative diseases characterized by progressive deterioration of cognitive and functional ability ${ }^{[1,2]}$. So, in addition to the person diagnosed, memory disorders also affect close relatives and the entire family. Therefore it is necessary to develop services that meet needs and expectations of patients and their families who can continue to live meaningfully and maintain quality of life with appropriate support during care ${ }^{[3]}$.

People with memory disorders (PMDs) and their family members face various challenges during their illness. Diagnosis is a turning point that creates significant psychosocial coping demands for the whole family ${ }^{[4-7]}$. Previous research shows how memory disorders change family roles and dynamics ${ }^{[5,8-10]}$. Interestingly, people with early-onset memory disorders and their families face slightly different challenges from those who are older at the time of onset ${ }^{[11-14]}$. Previous studies concerning the subjective experiences of PMDs focus on their challenges, coping strategies ${ }^{[15-18]}$, the diagnosis' impact on their selfhood and identity ${ }^{[11,19-21]}$, subjective reality ${ }^{[22,23]}$ and dignity ${ }^{[24,25]}$. Issues relevant to family members' experiences that have been studied include changes in relations as well as caregivers' challenges, well-being, burden and coping mechanisms ${ }^{[8,26-29]}$. Intrapersonal processes are usually of interest, and investigators highlight a need to understand the interpersonal and dyadic processes involved in giving and receiving care ${ }^{[30,31]}$. The challenge of living with memory disorders can be seen as a collaborative journey on which family members work together in response to their impact ${ }^{[32,33]}$. However, there is still limited knowledge of how whole families adjust to the life-altering situation evoked by memory disorders. Therefore, elucidating shared experiences of PMDs and their family caregivers (FCs) is important for understanding how they collaborate to manage their lives after diagnosis.

Our aim in the presented study was to examine shared experiences of PMDs and their FCs during the first years following diagnosis to construct a descriptive, substantive theory ${ }^{[34]}$. The study is part of a larger longitudinal study aiming to vividly portray life with progressive memory disorder from the viewpoint of PMDs and their FCs. The following research question was addressed: What factors are related to the mutual processes of managing the life-altering event?

\section{Methods}

\subsection{Study design}

A longitudinal, qualitative study design informed by grounded theory ${ }^{[34-36]}$ was used to formulate a theory about the experiences of PMDs and their FCs as they cope during the first few years after diagnosis.

\subsection{Study participants}

We recruited eight families for the study with members attending the memory clinic at a tertiary care hospital in Finland through purposive sampling, as follows. Selected participants were persons diagnosed with a progressive memory disorder $(n=8)$ and close relatives acting as caregivers $(n=8)$ who were willing and able to participate (see Table 1$)$. In a first recruitment phase the contact nurse at the memory clinic enquired about preliminary interest in participation among families of patients with newly diagnosed memory disorders. In a second recruitment phase the researcher phoned potential participants who had given their contact information and explained the study in more detail. First interviews were scheduled with those who expressed interest. The families were recruited during a 10-month period, and information gathered during the first round of data collection indicated that the participants from these families represented a sufficient range of characteristics and experiences for the purpose of the study.

\subsection{Data collection}

Data were collected using in-depth semi-structured ${ }^{[37]}$ interviews conducted in study participants' homes between June 2007 and April 2009. This article reports the results of the second, third and fourth phases of a larger study.

The interviews followed the principles of theoretical sampling ${ }^{[35,36]}$ in a cyclic process. Analyses of preliminary interviews guided subsequent interviews with both the respective and other participating families. The interviews became 
progressively more focused, and initial concepts were verified in later interviews. Interviews were conversational, lasting from 50 to 185 minutes (mean, 86 minutes). Seven families were each interviewed three times, and one family once. All families were offered the choice of being interviewed individually or jointly, and one family's choice to be individually interviewed was respected. Therefore, of 23 total interviews, 21 were joint interviews with both participants present, and one was conducted separately with each individual participant. First-round interviews were conducted $6-12$ months after confirmed diagnosis of a memory disorder. Second- and third-round interviews were conducted $7-9$ months after the initial interview. Except for the family interviewed once, this follow-up period lasted between 14 and 17 months.

All interviews were conducted by the first author, audio-recorded and transcribed verbatim. During the interviews, unstructured observations of study participants' interactions and emotions were noted to gather additional data for interpreting interview data. After each interview, the observations were written in a research diary. Data were collected until a sufficient level of theoretical saturation for the purpose of the study was reached, categories and their relationships had been developed, and no significant new information emerged in the latest interviews ${ }^{[35]}$.

Table 1. Characteristics of the study participants

\begin{tabular}{|c|c|c|c|c|c|c|c|c|c|}
\hline \multicolumn{6}{|c|}{ Person with memory disorder (PMD) } & \multicolumn{4}{|c|}{ Family caregiver (FC) } \\
\hline $\begin{array}{l}\text { Study } \\
\text { participant }\end{array}$ & Sex & $\begin{array}{l}\text { Age } \\
\text { (years)* }\end{array}$ & Diagnosis** & MMSE*** & Occupation $* * * *$ & $\begin{array}{l}\text { Study } \\
\text { participant }\end{array}$ & Relation & $\begin{array}{l}\text { Age } \\
\text { (years)* }\end{array}$ & Occupation**** \\
\hline PMD1 & Female & 65 & $\mathrm{AD}$ & $27 / 30$ & Old age pensioned & FC1 & Spouse & 73 & Old age pensioned \\
\hline PMD2 & Female & 74 & $\mathrm{AD}$ & $21 / 30$ & Old age pensioned & FC2 & Spouse & 82 & $\begin{array}{l}\text { Old age pensioned, } \\
\text { paid family } \\
\text { caregiver }\end{array}$ \\
\hline PMD3 & Female & 59 & $\mathrm{AD}$ & $20 / 30$ & $\begin{array}{l}\text { Sick leave, } \\
\text { disability } \\
\text { pensioned }\end{array}$ & FC3 & Spouse & 63 & $\begin{array}{l}\text { Unemployed, early } \\
\text { old age pensioned }\end{array}$ \\
\hline PMD4 & Male & 51 & $\mathrm{AD}$ & $14 / 30$ & $\begin{array}{l}\text { Sick leave, } \\
\text { disability } \\
\text { pensioned }\end{array}$ & FC4 & Spouse & 53 & $\begin{array}{l}\text { House wife, paid } \\
\text { family caregiver }\end{array}$ \\
\hline PMD5 & Female & 57 & LBD & $18 / 30$ & $\begin{array}{l}\text { Sick leave, } \\
\text { disability } \\
\text { pensioned }\end{array}$ & FC5 & Daughter & 39 & $\begin{array}{l}\text { Employed, paid } \\
\text { family caregiver }\end{array}$ \\
\hline PMD6 & Female & 68 & $\mathrm{AD}$ & $20 / 30$ & Old age pensioned & FC6 & Spouse & 63 & $\begin{array}{l}\text { Early old age } \\
\text { pensioned }\end{array}$ \\
\hline PMD7 & Male & 59 & LBD & $26 / 30$ & $\begin{array}{l}\text { Sick leave, } \\
\text { disability } \\
\text { pensioned }\end{array}$ & FC7 & Spouse & 56 & Employed \\
\hline PMD8 & Male & 55 & $\mathrm{AD}$ & $20 / 30$ & $\begin{array}{l}\text { Disability } \\
\text { pensioned }\end{array}$ & FC8 & Spouse & 52 & $\begin{array}{l}\text { Unemployed, paid } \\
\text { family caregiver }\end{array}$ \\
\hline
\end{tabular}

\subsection{Data analysis}

The first author subjected the data to constant comparative analysis ${ }^{[35,36]}$ using QSR NVivo computer-assisted qualitative data analysis software (versions 8 and 10). During the open coding phase, data gathered from each family were analyzed chronologically from the viewpoints of both participants (i.e. patient and caregiver). The transcripts were re-read in depth, meaningful pieces of data were identified and labelled with conceptual codes, and memos of preliminary remarks were written. In the axial coding phase, views of each family participant were analyzed separately, and any differences between families and dimensions of their experiences were identified. Conceptual codes were categorized and connected to conjunctive concepts, and memo-writing was continued to organize theoretical thought during the axial coding phase. In the selective coding phase, participants' experiences were merged into a core category. The open and axial coding phases occurred somewhat simultaneously, and the overall analysis included constant vacillation between the data and identified concepts. 


\subsection{Ethical considerations}

The Northern Ostrobothnia Hospital District Ethics Committee approved the study procedures (Eettmk: 107/2002, 241§ and Eettmk: 9/2006, 322§). Beneficence and non-maleficence, respect for participant autonomy, and justice guided all our actions ${ }^{[38,39]}$. We paid special attention to participants' wellbeing and autonomy because they were vulnerable, and this study focused on their emotionally-sensitive experiences ${ }^{[40]}$. Written informed consent was obtained from participants at the beginning of the longitudinal study-project. Their willingness to participate was confirmed during data collection. The participants were informed of their right to withdraw as desired at any point of the longitudinal study, with no consequences for their further care.

\section{Results}

A substantive theory of the mutual processes of managing life after a memory disorder diagnosis from the viewpoint of PMDs and their FCs is presented in Figure 1.

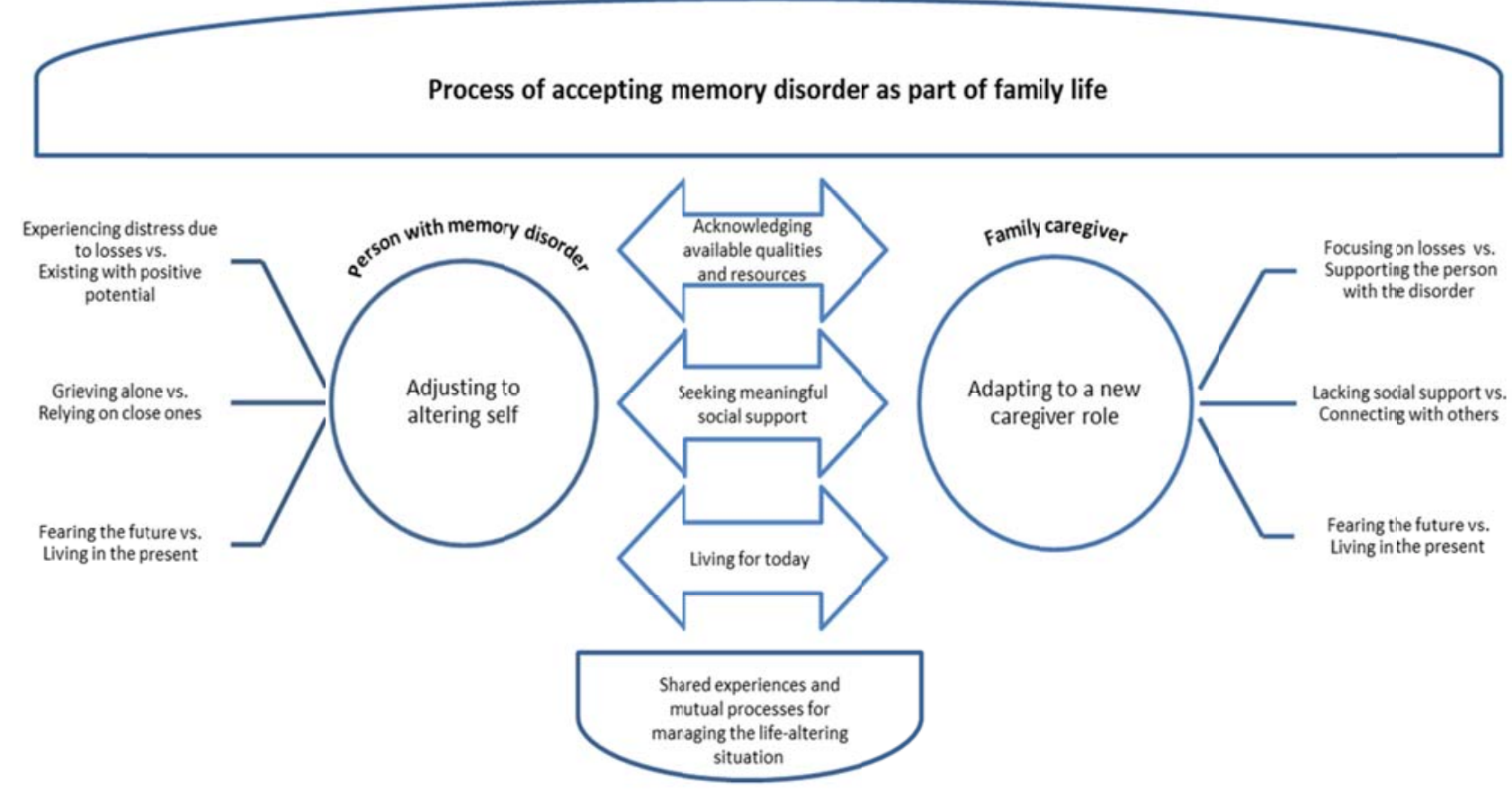

Figure 1. Schematic diagram of a substantive theory on the mutual processes of managing life after a memory disorder diagnosis

A core category, 'Process of accepting memory disorder as part of family life,' and related categories and subcategories were formulated from the data. For the PMD, adjusting to his or her altering self was central to learning to live with the disorder. For the FC, adopting the role of caregiver was essential to adjusting to family life changes and learning to live with their relative's disorder. The entire family, and not only the PMD, must cope with the diagnosis. The experiences of both PMD and FC were intertwined, thus forming a mutual adjustment process.

Three subcategories related to the categories 'Adjusting to altering self' and 'Adapting to a new caregiver role' were determined from the data. The subcategories 'Acknowledging available qualities and resources', 'Seeking meaningful social support,' and 'Living for today', describe the means whereby both PMDs and FCs seek new equilibrium and accept memory disorder as part of family life. The content of each subcategory comprises a continuum of positive and negative dimensions, i.e. adjustment and distress, respectively. 
The following sections present the results concerning the PMDs' perspectives, then describe the expressed experiences of FCs, and finally document their mutual processes for managing their life-altering situation.

\subsection{Adjusting to altering self: Patients' perspectives}

The memory disorders challenged the participating patients (PMDs) to: orient to their altering selves, receive help from others, and accept their feelings about an unpredictable future. These challenges involved distress due to losses and fears, but also adjustment, and feeling able to live a meaningful life with the disorder. For the patients, adjusting to their altering selves also involved acknowledging their own resources, having a supportive social network and focusing on the present (see Figure 1).

PMDs expressed a need to adjust to their changing life situation and accept their condition as an inescapable fact. Their experiences revealed somewhat gloomy feelings of resignation and accepting the diagnosis.

PMD4: When you have it, you have it. There's nothing you can do about it. I'm living my life little by little. My life goes as it goes, and eventually it comes to an end.

Adjusting was an emotionally demanding process for the PMD, invoking both repudiation and fear but also aspiration to accept the diagnosis and manage the altering situation with the help of others.

PMD1: At first I rejected it, but now ... I've accepted my disease. I know that I can get all the help that's available. And it's good that I've got a diagnosis, even though it's terrible. I feel the outrage and rejection, and my worst fears, but somehow... I've accepted all this, at least in some way. I’ve adjusted, I could say.

Although the disease was considered a crisis, participants tried to find an alternative perspective of hardship, which helped with adjustment to their altering selves.

PMD8: Things don't always go as they should. But usually things go alright, and I feel that this isn't that bad after all. This disease exists, and it was quite a shock, I can’t deny that.

Another PMD described how she aimed to see the positive side of changes, particularly the family's decision to move from their own familiar place with meaningful associations to sheltered accommodation.

PMD2: My resources have diminished, but I'm glad that we have this new apartment. Our old house was old-fashioned, so it wasn't easy to live there. I enjoyed the nature and our garden, but it was so difficult to continue living there.

A further factor that participants indicated was important for supporting adjustment was receiving sufficient straight forward information about their condition, expressed as follows by one PMD:

PMD7: I'm not grieving my situation. It's good the doctor has explained openly what this is all about. The doctors have asked me if I'm worried. I've said that I feel comfortable with myself and my disease. I know what I have; the doctor explained it to me, so I'm not worried.

\subsection{Adapting to a new caregiver role: Family caregivers' perspectives}

For the FC, learning to live with their relative's memory disorder was also a process with elements of both adjustment and distress. Components related to adopting the new role of FC included: acknowledging the potential of the PMD, finding a supportive social network, and focusing on the present (see Figure 1).

FCs described how they gradually adapted to changes in family life and learned their new role. Understanding and acknowledging the changes in their relative's functional capacity, and handling their own emotions, helped them to adjust.

FC4: Of course, this disease appears in everyday life; you can't deny that. But we've learned to live with it. There's no reason to stop living, and to worry about this. Sure it's sad that this had to come to our family, but we 
try to talk things over. After all we've lived two years with this. I've also had some difficult times and deal with my emotions. You can’t get along if you store everything inside. It becomes too distressing.

FCs' responsibilities in everyday life increased, and they needed to modify their daily and leisure activities. Some study participants carried out their responsibilities as FCs while remaining employed, which required balancing work and family.

FC7: Many times I've thought how nice it would be to stay home with you. On the other hand, many have said to me that it's good I have a job. Anyway, I've managed to stop the terrible worrying while I'm at work. I've noticed that you're getting along just fine at home. It was a huge change, since at first I was on sick leave, and later I was able to work again. My thoughts have cleared, and I feel we can live with this. You're able to stay at home during the day. Sometimes my colleagues at work ask how he’s managing at home, and I say he’s doing all right.

\subsection{Mutual processes used for managing the life-altering situation}

\subsubsection{Acknowledging available qualities and resources}

This subcategory describes how both PMDs and FCs face functional changes due to diagnosis, and how they seek a new equilibrium in their altering situation. PMDs balanced experiencing distress due to losses with aspiring toward a potentially positive existence, while FCs were challenged with supporting their relative instead of focusing on troubles and losses (see Figure 1).

PMDs aspired to make the most of their potential in several ways. Meaningful everyday activities, and reciprocally helping others, were important for PMDs and made them feel valuable. They wanted to be regarded as themselves, and not according to their condition.

PMD6: I'll help our neighbor. She's a divorced old lady and we know each other really well. Sometimes we drink evening coffee together, talk and watch TV. I think it's really pleasant for her. And I'll take her shopping and to the doctor and help her with her prescriptions. We've been neighbors for so long and our friendship is mutual.

PMDs wanted to be seen as competent people with potential and FCs supported this by encouraging them to be active and participate.

FC4: He walks alone quite a lot, and rides a bike. We haven’t had any problems with this.

PMD4: I walk with our dog a lot. It's good to walk there. I can go where I want.

FC4: It's been really nice to see that he's managing. We were told that I wouldn't be able to let him walk alone, but it's not like that at all. I've accompanied him and noticed that he's doing just fine out there, walks quite long rounds.

PMD4: If I didn’t go for a walk every day, I might not want to bother at all.

Sometimes PMDs' desire to retain an active and independent lifestyle caused concern for family members, and the PMDs needed to accept a need for surveillance, as one PMD revealed.

PMD1: One day I went cycling and rode a really long way; it took me a long time. I don't like to announce beforehand where I'm going and we don't have that kind of arrangement yet. Well, when I arrived home, my husband was quite nervous. He had told our children that I was missing. I didn't have my mobile phone with me. Of course I understand that they were really nervous and worried for me. But then we've agreed that when I leave home I'll carry my phone with me from now on, even though I don't like it too much. I understand that my family wants to know where I am and everything's OK.

PMDs also expressed desires to retain autonomy, control their affairs and determine how they were treated. 
PMD5: It was this young doctor who suggested the medicated plaster for me. I refused since I don't want anything on my skin. I'm kind of a nature person; I like to wander outdoors and all that. I can take the pills, but not the plaster.

For another PMD it was important that she could decide who was told about her diagnosis, reflecting not only a need to maintain control over her personal concerns, but also feelings of shame, and fear of being stigmatized.

PMD6: Why on earth can't I carry this burden myself? My burden increases when I tell other people about this. It won't reduce my burden if my dear friends and relatives know and have to carry my load. As long as I'm competent, I want to make my own decisions. I think it’s fair.

FC6: Sometimes it just feels a bit strange since at the health center they don't know anything about your diagnosis. You've resisted telling them.

PMD6: Well, it's a place I used to work.

For an elderly patient and her husband, changes due to memory disorder were connected to overall health changes associated with ageing. Therefore, they were less distressed by losses than younger participants. For the patient, health meant managing daily life as well as possible, with the help of her spouse, and retaining sufficient functionality and independence.

PMD2: But so far, I think that everything is just fine for us. We are managing quite well. We don't need much help since he [husband] is taking care of things. He tries his best to take care of me, as I've become a bit sluggish. FC2: I feel that we go forward quite optimistically. It's just if we stay healthy and in decent condition, I think we'll do all right. We'll get our pension; that covers our health care expenses. We don't need benefits from society. So we have no problems at all, if we just stay healthy.

PMD2: That's the most important thing. Health. When you're this old it starts to worsen. One day might be better, but another could be really lousy.

Although changes in daily life could cause tension among FCs, they emphasized the ways they adjusted their approaches and actions according to the needs of the PMDs, manifested in desires to: be supportive in hardship and understanding of everyday difficulties, encourage and enable their relative to remain active even with the disorder, and advocate and focus on the PMD's capabilities and strengths. This positive orientation was also apparent in the FCs' aims to support the competence of the PMDs appreciatively and respectfully.

PMD5: I feel sad for the boys [grandsons], because they see how sluggish I am.

FC5: I think you're doing just fine with my sons. I'm sure they won't even think like that.

PMD5: But I'm making so many mistakes; they must notice that.

FC5: There aren't so many mistakes; some in writing, yes, but there aren't so many difficulties yet.

PMD5: If the boys are asking me the time, I can’t always tell them. I don't know that.

FC5: You don’t need to worry about that at all; the boys can check the time by themselves.

This supportive attitude was also apparent in another family, where a FC tried to point out the existing resources and competencies of the PMD.

PMD4: We can still work in our son's farm, but there's machinery that I don't dare to use anymore. I remember one time when I started... I couldn't make any of them work. I felt so fed up and I gave up everything.

FC4: But you've still done something.

PMD4: Well something, yes, but...

FC4: You've driven the tractor and baler, made hay bales and been a helping hand for our son.

PMD4: Well, but he already knows everything.

PMD4: Yes, but he still needs help and you've helped him. 


\subsubsection{Seeking meaningful social support}

This subcategory describes the meaning of social support for both PMDs and FCs. Meaningful social support, either from close ones or wider social networks generated feelings of contentment. In contrast, a lack of social support or withdrawal from social relationships left study participants alone with their thoughts and experiences (see Figure 1).

Relying on relatives, such as spouses, children and grandchildren formed a significant form of support for PMDs. For them it was important to be accepted as they were. Study participants also expressed how the difficulties have made the mutual relationships stronger.

PMD1: I feel that our companionship has become stronger. I feel that we accept each other as we are. Of course I'm a bit strained with my disease, and wonder how you're doing with me.

FC1: It's important to understand all this; at least, I try to understand. Our children have worried about my resources and asked how I'm managing and do I have difficult times. I've said, and I really mean it, that I don't feel that our life situation is difficult. We still have a lot of elements for good life. And many things are pretty well.

Another PMD shared her perceptions of this crucial aspect of social support, as follows:

PMD6: I have lot of important things in my life, things that give me reason to live. Our grandchildren need me. And I think I'm important for my husband too. It may be that you are even more important in sickness. We've always rowed this boat together. I'm so happy that we still care and love each other and show it. Our good marriage is a great resource. I don't think he would loosen his hand from my hand, even though I'm diseased.

The study participants needed practical support from other people to meet challenges in everyday life. FCs' roles in promoting safety and assisting in situations that required social interaction were essential for PMDs.

PMD6: I'm afraid that I could isolate myself. Therefore I think it's positive that I like to visit our friends. It's just that I can't go alone. First of all, I don't know how to drive there since it's hard for me to navigate the city. And if there are situations when I don't know what to say, my husband is my safeguard and we'll talk together.

FC6: When I'm there with her, I can then...

PMD6: ...reinforce me.

FC6: Yes, and clarify things and be an aide-memoire for you.

While PMDs considered social support from closest family members most significant, FCs thought it important to get meaningful support from others, such as peers, neighbors and health professionals, to help them cope. Peer support provided opportunities to share experiences with others in similar situations.

FC7: What I need is more peer support. That course that we took after the diagnosis was really wonderful! I would like to hear how those people are doing now. It would be really wonderful.

For younger family caregivers it was meaningful to participate in peer support groups, even when they were not specifically oriented towards their needs.

FC3: We had a chance to attend a rehabilitation course and it was also important for me as a family caregiver. I've also attended a course once a month while she [the FC's wife] joins a physical exercise group. Although the other family caregivers are older than me I still get on quite well there.

Possibilities to exchange experiences and ventilate feelings in everyday relationships were important, as expressed by another FC:

FC8: What I need is just to chat and exchange experiences. I don't need anything special. I've been talking with our neighbors. 


\subsubsection{Living for today}

This subcategory comprises identical themes for both the PMD and FC. Living in the present and focusing on the good things in life positively counterbalanced fears of the unknown future (see Figure 1). The progressive nature of the disorder shadowed study participants' visions for the future. The progress of the disease and its effects on family life, concern about how the FC would manage with the close one's condition and the FC's own resources were major concerns for study participants, which they aimed to overcome by drawing attention to positive elements of the present situation. FCs had an important role to play in encouraging the PMDs.

FC1: I think you almost daily wonder how I'll manage with you.

PMD1: It's just that I don't know where this will end and what it will bring. I agree that I ask quite often how you'll manage with me. I've said to him [husband] that when you don't have strength anymore, you can take me to the nursing home. I don't want him to be burdened by me.

FC1: I don't want to anticipate and worry about what's going to happen. There are things that are out of our hands and there's no point in letting it shadow the present. We have discussed this, and it's not that we're cheating ourselves. We have to focus on the positive elements in our lives.

The FCs' perseverance was reflected in the determination to live one day at a time and focus on PMD's strengths and capabilities. FCs also made efforts to motivate their relative and themselves with various stimuli:

FC4: We just live a normal life. We exercise quite a lot, go dancing and shopping together. We haven’t isolated ourselves and stayed inside four walls. It's quite easy to give in and go nowhere. But we haven't given up yet. We'll go as long as we can. And I've said that we live one day at a time since no-one can foresee the future. I've noticed that stimuli are very important. What he needs is that I accompany him [husband]. We talk every day and everything. We plan things together. Life must go on. You can't stop living. You need to go forward. Our children agree with this; they encourage us to go and live our lives just like we've used to live. We would get into a bad condition if we just stayed home. I know I would be depressed if I'm not active. Sometimes there are difficult times, of course, but you just have to raise yourself somehow. If the family caregiver gets depressed, then everything falls through.

For PMDs, familiar daily activities were meaningful. Managing their life-altering situation meant an objective to live a common everyday life and continue to pursue activities that were previously meaningful. PMDs were also motivated to take better care of their physical condition.

PMD7: Well, I've planned that I need to be in good shape, exercise and so on. That's important. Then I need to eat proper, healthy food. Sometimes I have a desire for something, like smoked herring. When I gave up my driver's license I decided that we'll take care of things together, go shopping to the marketplace and market hall. That's what I used to do when I was still working. I want to live a normal life.

Hopes for the future were related to thoughts that things would stay the same for as long as possible, and that everyday life would go well. Elderly study participants had also specifically hoped to be able to live at home as long as possible.

FC2: Anyway, we've managed quite smoothly, I would say.

PMD2: Yes we have. And I hope everything continues the same way.

FC2: That's what I hope too, that's what we hope. We'd like to stay living at home; hopefully we don't have to end up in long-term care.

Families also hoped that the condition would progress slowly, with the help of medication, or even that there may be some recovery.

FC6: We'll see. Our spark of hope is the medication. The doctor thought that it could even recover a little, not just slow down her condition, but increase her functionality. 
However, hopes for the future were rather limited and families focused more on their life in the present.

\section{Discussion}

The results of our study indicate that managing a life-altering situation is a mutual process in a family. Crucial identified factors in the process of accepting a memory disorder as part of family life and managing this life-altering situation were: recognizing and understanding changes in oneself and family dynamics, acknowledging the potential of the PMD and maintaining an active everyday life, having opportunities to obtain sufficient social support and mutual relationships, confirming hope, and relieving despair and fear of the future. These findings serve as a basis for a substantive theory of mutual social processes when accepting a memory disorder as part of family life.

For the person diagnosed with a memory disorder (PMD), the essential challenge was to adjust to his or her altering self, whereas family members faced the challenge of adapting to the new role of caregiver. In these respects, our results support previous indications that managing identity and sense of self is a significant coping task for the PMD ${ }^{[4,11,15,21]}$ and that adaptation to new roles and responsibilities of caregiving poses challenges for family caregivers (FCs) ${ }^{[5,8,10,12,41]}$. The processes of adjusting to altering self and adopting the role of caregiver were intertwined as interpersonal processes comprising a continuum of adjustment and distress. Previous research has addressed similar tensions resulting when individuals try to balance the negative and positive aspects of living with a memory disorder ${ }^{[4,42]}$. Both the PMD and FC face multiple changes and losses, but at the same time they actively strive to overcome the problems and adjust to the altering situation.

Mutual factors related to managing their life-altering situation during the first few years after diagnosis were: acknowledging available qualities and resources, seeking meaningful social support, and living for today. Despite the deterioration of functional capacity, PMDs wanted to be seen as competent, and expressed a desire to retain autonomy concerning their own matters. Similarly, as noted earlier ${ }^{[43]}$, our PMD study participants wanted to be regarded as themselves, not according to their condition. The results of our study support the findings of previous studies indicating that PMDs attempt to maintain their prior sense of self ${ }^{[20]}$, and remain valued and competent ${ }^{[44]}$, when managing changes in their self. In accordance with Steeman et al. ${ }^{[44]}$, our results also indicate that others could foster the PMDs' experience of being valued by treating them as competent individuals and thus helping them maintain equilibrium. Our study also indicated that reciprocity in relationships, and giving help to, as well as receiving it from, others was important for PMDs, representing their need to be valuable to others, as found in earlier studies ${ }^{[44]}$. Most FCs supported and encouraged PMDs, and their understanding attitudes promoted the PMDs' images of self-competence and created a positive family atmosphere. It is possible that FCs' negative thoughts and feelings of burden could cause them to focus on their relatives' weaknesses, creating a vicious cycle in the family, during which the FCs' negative orientation lead to negative responses and actions from the PMD, exacerbating tension. Previous research has shown that good quality of daily relationships and positive reciprocal communication can promote FCs' wellbeing ${ }^{[31,45,46]}$ and support the positive adjustment of PMDs. It has also been found that enhanced relationship quality can maintain better emotional wellbeing of both the PMD and the FC, which can lead to more positive experiences of living with a memory disorder ${ }^{[9]}$.

Despite their changing situation causing distress, both PMDs and FCs felt that they have enough strength to get through difficult times, and that together, as a family, they would cope. Working through the difficulties is a collaborative effort during which family members commit to the mutual relationship in spite of the disorder ${ }^{[33]}$. Our findings corroborate earlier findings that although memory disorders may adversely affect family relationships ${ }^{[9]}$, difficulties may also strengthen them and increase closeness between family members. Meaningful social support, especially from close relatives, was an important mainstay for the families, and promoted feelings of contentment with life. This finding is also confirmed by earlier studies ${ }^{[5,15]}$. As also noted previously ${ }^{[15]}$, possibilities to obtain meaningful social support from others, such as friends, peers and health care professionals, assists with managing the life-altering situation. Talking about one's experiences and feelings can also support coping, and help people make sense of their situation ${ }^{[10,15,19]}$. However, 
not all are able or even want, to share their experiences outside of the family, and there may be different individual needs within the family to vent one's feelings. Efforts to keep the diagnosis a private matter could reflect a fear of being stigmatized $^{[47]}$.

Our study confirmed findings of earlier studies ${ }^{[5,10]}$ that fears and concerns about the future shadowed the families' life. PMDs worried about how their FCs would manage with them. PMDs' concerns about being a burden to their FCs ${ }^{[18]}$ affect their interpersonal relations. As a positive counterbalance to fear of the future, families focused on common everyday life, existing resources, and all the good things about their lives. Quality of family life and management of their situation were improved by a willingness to face the future one day at a time and focus on positive things, as noted in earlier studies ${ }^{[4,5,10,33]}$. Although living with memory disorders means balancing losses with maintaining equilibrium ${ }^{[44]}$, and hope with despair ${ }^{[42]}$, it is still manageable ${ }^{[43]}$. The families' perseverance was apparent in their resilient spirits and their refusal to give up. Mutual hopes for the future were expressed in goals to maintain current health and quality of life as long as possible. Previous research shows similar aspects of hope for both PMDs and their FCs ${ }^{[48,49]}$. Balancing hope and despair, and maintaining equilibrium, could be considered crucial for adjusting to life with a memory disorder ${ }^{[42,49]}$.

Our findings also support the results of previous studies demonstrating differences in challenges faced by families living with early- versus late-onset memory disorders. Younger adults consider the experience, involving lifestyle changes and new roles, a more significant shift than older adults ${ }^{[12-14]}$. Memory disorders bring physical and cognitive decline, fear of losing control over one's life, and the notion of imminent mortality, all of which are typically associated with old age ${ }^{[50]}$.

This study complements previous knowledge of mutual processes of managing life-altering events by bringing together the experiences of both PMDs and FCs. We present a theoretical formulation that describes the factors related to these mutual processes and thus contributes to the knowledge base concerning families' experiences during the first years following a family member's diagnosis with memory disorder.

\section{Strengths, limitations and ethical questions}

We aimed to ensure trustworthiness of the study by paying attention to both standard criteria for qualitative studies (i.e. credibility, dependability and transferability) ${ }^{[51]}$ and the quality conditions presented by Corbin and Strauss ${ }^{[35]}$. The credibility of the study was strengthened by obtaining as rich variation of data as possible. Although the sample size was small, study participants formed a heterogeneous group with diverse backgrounds and experiences. Furthermore, the longitudinal research design and repeated interviews with unstructured observations provided in-depth and diverse understanding of study participants' experiences. Prolonged data collection and analysis ensured saturation of the categories we developed. Dependability was ensured by acquiring insights into the focal phenomena by conducting interviews in a cyclic evolving process and the co-authors continuously discussing both the analysis and results. We enhanced transferability by describing the research process as clearly as possible and presenting findings with appropriate quotations for readers to evaluate the relevance of the research. Quality conditions were met by using research methods that were consistent with the purpose of the study and by the principal investigator (first author): carefully planning the research procedure, preparing in advance for the research methods and possible ethical dilemmas before entering the field, keeping a research diary and writing memos to increase self-awareness of possible biases, assumptions and interpretations during the data collection. Furthermore, she aimed to preserve situational sensitivity and personal responsiveness when collecting the data, in order to obtain a profound understanding of study participants' experiences. The use of computerassisted data analysis software provided means to track the analytic path and thus enhanced transparency of the study ${ }^{[52]}$.

Ethical issues during the data collection were related to the situation of the family and the researcher's role. The challenging life situations families were experiencing called for empathy and sensitivity when recruiting and interviewing study participants. We aimed to minimize the distress and burden of study participants by conducting the interviews in their homes. Furthermore, interviews were mainly conducted jointly, according to participants' wishes. When offered the 
option of individual interviews, participants relayed their ability to discuss their experiences openly with their relative. However, joint interviews may have prevented the disclosure of some difficult issues. Furthermore, on some occasions, the FC may have slightly dominated the interview, especially if verbalizing was difficult for the PMD, or the FC wanted to vent his or her feelings of burden. From the researchers' perspective, interviews were confidential conversations during which both study participants' experiences were sufficiently revealed and a shared construction of the family life situation was produced. At times, the FC had an important role as an aide-memoire and supporter, thus protecting the well-being of the PMD. Furthermore, the joint interviews may be considered a factor confirming the trustworthiness of the study. Clearly, researchers' behavior and activities can potentially both bias results and upset vulnerable people when exploring sensitive subjects. Thus, care was taken in all interviews to maintain an ethically appropriate balance between directing conversations to address the study question and paying empathetic attention to the participants' well-being, emotional resources and stories.

\section{Conclusions and implications for practice}

Our study illustrates the mutual processes involved in families accepting memory disorder as part of their lives during the first years after diagnosis. Several conclusions can be drawn from the results. It is important for health care services to pay attention to the family situation. Family-centered interventions that support family member collaboration in adjusting to the altering situation, and seeking new equilibrium in life, are needed. Crises can provide opportunities for families to learn new life skills. Offering sufficient support for family members tailored to according to their needs can help to maintain optimal individual, and therefore family, wellbeing. Families could learn, from such support, that despite losses, they can adjust and find positive elements that could replace their distress. Psycho-educational programs for individuals and couples are means of support that could assist with coping ${ }^{[33-55]}$, but each individual's needs should be considered. Further research is needed to generate deeper understanding of family dynamics to develop services that meet the needs of both individuals and the family as a whole. Also, the differences in needs of families of people with early-onset and late-onset memory disorders require further investigation.

\section{Acknowledgements}

We thank all study participants for their contributions to this study. The study was financially supported by the Finnish Cultural Foundation, and the Finnish Association of Nursing Research and EVO-grants (special state funding for clinical research).

\section{References}

[1] Prince M, Bryce R, Albanese E, Wimo A, Ribeiro W, Ferri CP. The global prevalence of dementia: A systematic review and metaanalysis. Alzheimer's \& Dementia. 2013; 9(1): 63-75.e2. PMid: 23305823 http://dx.doi.org/10.1016/j.jalz.2012.11.007

[2] Bouchard RW. Diagnostic criteria of dementia. Canadian Journal of Neurological Sciences. 2007; 34(Suppl 1): 11-18. PMid: 17469675

[3] World Health Organization. Dementia: a Public Health Priority. World Health Organization and Alzheimer's Disease International. 2012. Available from: http://apps.who.int/iris/bitstream/10665/75263/1/9789241564458_eng.pdf

[4] Robinson L, Clare L, Evans K. Making sense of dementia and adjusting to loss: Psychological reactions to a diagnosis of dementia in couples. Aging \& Mental Health. 2005; 9(4): 337-347. PMid: 16019290 http://dx.doi.org/10.1080/13607860500114555

[5] Pesonen H, Remes A, M., Isola A. Diagnosis of dementia as a turning point among Finnish families: A qualitative study. Nursing \& Health Sciences. 2013; 15(4): 489-496. PMid: 23725577 http://dx.doi.org/10.1111/nhs.12059

[6] Steeman E, de Casterle BD, Godderis J, Grypdonck M. Living with early-stage dementia: A review of qualitative studies. Journal of Advanced Nursing. 2006; 54(6): 722-738. PMid:16796664 http://dx.doi.org/10.1111/j.1365-2648.2006.03874.x

[7] Vernooij-Dassen M, Derksen E, Scheltens P, Moniz-Cook E. Receiving a diagnosis of dementia: The experience over time. Dementia. 2006; 5(3): 397-410. http://dx.doi.org/10.1177/1471301206067114

[8] Adams KB. The transition to caregiving: The experience of family members embarking on the dementia caregiving career. Journal of Gerontological Social Work. 2006; 47(3-4): 3-29. PMid: 17062520 http://dx.doi.org/10.1300/J083v47n03_02

Published by Sciedu Press 
[9] Ablitt A, Jones GV, Muers J. Living with dementia: A systematic review of the influence of relationship factors. Aging \& Mental Health. 2009; 13(4): 497-511. PMid: 19629774 http://dx.doi.org/10.1080/13607860902774436

[10] O'Shaughnessy M. Changes in the couple relationship in dementia care: Spouse carers' experiences. Dementia. 2010; 9(2): 237-258. http://dx.doi.org/10.1177/1471301209354021

[11] Harris PB, Keady J. Selfhood in younger onset dementia: Transitions and testimonies. Aging \& Mental Health. 2009; 13(3): 437-444. PMid: 19484608 http://dx.doi.org/10.1080/13607860802534609

[12] Svanberg E, Spector A, Stott J. The impact of young onset dementia on the family: A literature review. International Psychogeriatrics. 2011; 23(3): 356-371. PMid: 20735892 http://dx.doi.org/10.1017/S1041610210001353

[13] Harris PB, Keady J. Living with early onset dementia: Exploring the experience and developing evidence-based guidelines for practice. Alzheimer's Care Quarterly. 2004; 5(2): 111-122.

[14] van Vliet, Deliane, E., Bakker C, T,C.M., J. Impact of early onset dementia on caregivers: A review. International Journal of Geriatric Psychiatry. 2010; 25(11): 1091-1100. PMid: 20957692 http://dx.doi.org/10.1002/gps.2439

[15] Preston L, Marshall A, Bucks RS. Investigating the ways that older people cope with dementia: A qualitative study. Aging \& Mental Health. 2007; 11(2): 131-143. PMid: 17453546 http://dx.doi.org/10.1080/13607860600844572

[16] Mok E, Lai C, Wong F, Wan P. Living with early-stage dementia: The perspective of older Chinese people. Journal of Advanced Nursing. 2007; 59(6): 591-600. PMid: 17727403 http://dx.doi.org/10.1111/j.1365-2648.2007.04368.x

[17] Gilmour JA, Huntington AD. Finding the balance: Living with memory loss. International Journal of Nursing Practice. 2005; 11(3): 118-124. PMid: 15853790 http://dx.doi.org/10.1111/j.1440-172X.2005.00511.x

[18] Mazaheri M, Eriksson L, E., Heikkilä K, Nasrabadi A, Nikbakht, Ekman S, Sunvisson H. Experiences of living with dementia: Qualitative content analysis of semi-structured interviews. Journal of Clinical Nursing. 2013; 22(21): 3032-3041. PMid: 23815315 http://dx.doi.org/10.1111/jocn.12275

[19] Pearce A, Clare L, Pistrang N. Managing sense of self. Dementia. 2002; 1(2): 173-192. http://dx.doi.org/10.1177/147130120200100205

[20] Clare L. Managing threats to self: Awareness in early stage Alzheimer's disease. Social Science and Medicine. 2003; 57(6): 1017-1029. PMid: 12878102 http://dx.doi.org/10.1016/S0277-9536(02)00476-8

[21] Harman G, Clare L. Illness representations and lived experience in early-stage dementia. Qualitative Health Research. 2006; 16(4): 484-502. PMid 16513992 http://dx.doi.org/10.1177/1049732306286851

[22] Lawrence V, Samsi K, Banerjee S, Morgan C, Murray J. Threat to valued elements of life: The experience of dementia across three ethnic groups. The Gerontologist. 2011; 51(1): 39-50. PMid: 20724657 http://dx.doi.org/10.1093/geront/gnq073

[23] Hulko W. From 'not a big deal' to 'hellish’: Experiences of older people with dementia. Journal of Aging Studies. 2009; 23(3): 131-144. http://dx.doi.org/10.1016/j.jaging.2007.11.002

[24] Tranvåg O, Petersen KA, Nåden D. Crucial dimensions constituting dignity experience in persons living with dementia. Dementia. 2014; 17. PMid: 24742877 http://dx.doi.org/10.1177/1471301214529783

[25] van Gennip IE, Pasman HRW, Oosterveld-Vlug MG, Willems DL, Onwuteaka-Philipsen BD. The development of a model of dignity in illness based on qualitative interviews with seriously ill patients. International Journal of Nursing Studies. 2013; 50(8): 1080-1089. http://dx.doi.org/10.1016/j.ijnurstu.2012.12.014

[26] Quinn C, Clare L, Pearce A, van Dijkhuizen M. The experience of providing care in the early stages of dementia: An interpretative phenomenological analysis. Aging \& Mental Health. 2008; 12(6): 769-778. PMid: 19023728 http://dx.doi.org/10.1080/13607860802380623

[27] Papastavrou E, Kalokerinou A, Papacostas SS, Tsangari H, Sourtzi P. Caring for a relative with dementia: Family caregiver burden. Journal of Advanced Nursing. 2007; 58(5): 446-457. PMid: 17442030 http://dx.doi.org/10.1111/j.1365-2648.2007.04250.x

[28] Papastavrou E, Tsangari H, Karayiannis G, Papacostas S, Efstathiou G, Sourtzi P. Caring and coping: The dementia caregivers. Aging \& Mental Health. 2011; 15(6): 702-711. PMid: 21547752 http://dx.doi.org/10.1080/13607863.2011.562178

[29] Kim H, Chang M, Rose K, Kim S. Predictors of caregiver burden in caregivers of individuals with dementia. Journal of Advanced Nursing. 2012; 68(4): 846-855. PMid: 21793872 http://dx.doi.org/10.1111/j.1365-2648.2011.05787.x

[30] Nolan MR, Davies S, Brown J, Keady J, Nolan J. Beyond 'person-centred' care: A new vision for gerontological nursing. Journal of Clinical Nursing. 2004; 13(3): 45-53. PMid: 15028039 http://dx.doi.org/10.1111/j.1365-2702.2004.00926.x

[31] Braun M, Scholz U, Bailey B, Perren S, Hornung R, Martin M. Dementia caregiving in spousal relationships: A dyadic perspective. Aging \& Mental Health. 2009; 13(3): 426-436. PMid: 19484607 http://dx.doi.org/10.1080/13607860902879441

[32] Hellström I, Nolan M, Lundh U. 'We do things together’: A case study of ‘couplehood’ in dementia. Dementia. 2005 ; 4(1): 7-22. http://dx.doi.org/10.1177/1471301205049188 
[33] Davies JC. Preserving the “us identity” through marriage commitment while living with early-stage dementia. Dementia. 2011; 10(2): 217-234. http://dx.doi.org/10.1177/1471301211398991

[34] Glaser, BG, Strauss, AL. The Discovery of Grounded Theory: Strategies for Qualitative Research. New York, USA: Aldine de Gruyter; 1967.

[35] Corbin, J, Strauss, AL. Basics of Qualitative Research: Techniques and Procedures for Developing Grounded Theory. 3rd ed. California, USA: Sage Publications, Inc.; 2008.

[36] Engward H. Understanding grounded theory. Nursing Standard. 2013; 28(7): 37-41. PMid: 24128248 http://dx.doi.org/10.7748/ns2013.10.28.7.37.e7806

[37] Hesse-Biber, SN, Leavy, P. The Practice of Qualitative Research. 2nd ed. California, USA: Sage Publications, Inc.; 2011.

[38] Pesonen H, Remes A, M., Isola A. Ethical aspects of researching subjective experiences in early-stage dementia. Nursing Ethics. 2011; 18(5): 651-661. PMid: 21893576 http://dx.doi.org/ 10.1177/0969733011408046

[39] McIlfatrick S, Sullivan K, McKenna H. Exploring the ethical issues of the research interview in the cancer context. European Journal of Oncology Nursing. 2006; 10(1): 39-47. PMid: 15993646 http://dx.doi.org/10.1016/j.ejon.2005.04.002

[40] Liamputtong, P. Researching the Vulnerable. A Guide to Sensitive Research Methods. London: Sage Publications Ltd.; 2007.

[41] Sanders S, Power J. Roles, responsibilities, and relationships among older husbands caring for wives with progressive dementia and other chronic conditions. Health \& Social Work. 2009; 34(1): 41-51. PMid: 19281101

[42] Clare L. We'll fight it as long as we can: Coping with the onset of Alzheimer's disease. Aging \& Mental Health. 2002; 6(2): 139-148. PMid: 12028882 http://dx.doi.org/10.1080/13607860220126826

[43] Beard RL, Knauss J, Moyer D. Managing disability and enjoying life: How we reframe dementia through personal narratives. Journal of Aging Studies. 2009; 23(4): 227-235. http://dx.doi.org/10.1016/j.jaging.2008.01.002

[44] Steeman E, Godderis J, Grypdonck M, De Bal N, Dierckx de Casterle B. Living with dementia from the perspective of older people: Is it a positive story? Aging \& Mental Health. 2007; 11(2): 119-130. PMid: 17453545 http://dx.doi.org/10.1080/13607860600963364

[45] Carbonneau H, Caron C, Desrosiers J. Development of a conceptual framework of positive aspects of caregiving in dementia. Dementia. 2010; 9(3): 327-353. http://dx.doi.org/10.1177/1471301210375316

[46] Braun M, Mura K, Peter-Wight M, Hornung R, Scholz U. Toward a better understanding of psychological well-being in dementia caregivers: The link between marital communication and depression. Family Process. 2010; 49(2): 185-203. PMid: 20594206 http://dx.doi.org/10.1111/j.1545-5300.2010.01317.x

[47] Hellström I, Nolan M, Lundh U. Awareness context theory and the dynamics of dementia: Improving understanding using emergent fit. Dementia. 2005; 4(2): 269-295. http://dx.doi.org/10.1177/1471301205051096

[48] Wolverson EL, Clarke C, Moniz-Cook E. Remaining hopeful in early-stage dementia: A qualitative study. Aging \& Mental Health. 2010; 14(4): 450-460. PMid: 20455121 http://dx.doi.org/10.1080/13607860903483110

[49] Cotter VT. Hope in early-stage dementia: A concept analysis. Holistic Nursing Practice. 2009; 23(5): 297-301. PMid: 19713788 http://dx.doi.org/10.1097/HNP.0b013e3181b66d4f

[50] Settersten R.A. Jr., Trauten ME. The New Terrain of Old Age: Hallmarks, Freedoms, and Risks In: Bengtson VL, Silverstein M, Putney NM, Gans D, editors. Handbook of Theories of Aging. New York: Springer Publishing Company; 2009; p. 455-469.

[51] Graneheim UH, Lundman B. Qualitative content analysis in nursing research: Concepts, procedures and measures to achieve trustworthiness. Nurse Education Today. 2004; 24(2): 105-112. PMid: 14769454 http://dx.doi.org/10.1016/j.nedt.2003.10.001

[52] Holloway, I. Qualitative Research in Health Care. Berkshire, England: Open University Press, McGraw-Hill Education; 2005.

[53] Gaugler JE, Gallagher-Winker K, Kehrberg K, Lunde AM, Marsolek CM, Ringham K, et al. The memory club: Providing support to persons with early-stage dementia and their care partners. American Journal of Alzheimer's Disease and Other Dementias. 2011; 26(3): 218-226. PMid: 21362755 http://dx.doi.org/10.1177/1533317511399570

[54] Ducharme F, Beaudet L, Legault A, Kergoat M, Lévesque L, Caron C. Development of an intervention program for Alzheimer's family caregivers following diagnostic disclosure. Clinical Nursing Research. 2009; 18(1): 44-67. PMid: 19208820 http://dx.doi.org/10.1177/1054773808330093

[55] Mountain GA, Craig CL. What should be in a self-management programme for people with early dementia?. Aging \& Mental Health. 2012; 16(5): 576-583. PMid: 22360274 http://dx.doi.org/10.1080/13607863.2011.651430 